\title{
ИДЕАЛ БЕЗБРАЧИЯ В ПЛАТОНИЗМЕ: оТ ПЛАТОНА К ПЛОТИНУ
}

\begin{abstract}
А.М. Шаталович
Тема семьи и брака, по мнению автора статьи, недостаточно представлена в историко-философском измерении, по сравнению, например, с массивом социологических или психологических исследований. Между тем данная ниша содержит существенный потенциал в философско-культурологическом ракурсе. Так, в рамках исследования философских истоков европейской культуры интерес представляет платонический идеал безбрачия, оказавший влияние на становление христианских аскетических традиций «духовного» брака человеческой души и Бога, а также традиций монашеской «духовной» семьи. Об этом в частности пишет А.Лосев: «Христианский платонизм прямо запрещает и семью, и брак, и любовь. [...] христианский платонизм есть монашество» [7, с.848]. С. Троицкий в своем исследовании делает вывод, что пренебрежение браком у некоторых церковных авторов коренится по наследству от античности в излишнем превознесении разума, являясь своего рода данью, «которую заплатили древние церковные писатели языческой школе» [20, с. 121-122]. Однако вопрос формирования самого идеала безбрачия в философских исследованиях платонизма и неоплатонизма (П. Адо, В. Асмус, П. Блонский, В. Виндельбанд, А. Лосев, Вл. Соловьев, К. Поппер, В.Эрн) подробно не анализируется. В связи с этим, цель данной статьи-выявить идейные истоки, философские основания и ключевые этапы формирования идеала безбрачия в платонизме.

В качестве основных определений брака в данной работе приняты следующие. В широком смысле, брак-социально организованные половые отношения между мужчиной и женщиной. В узком смысле,
\end{abstract}

Актуальні проблеми духовності:

зб. наук. праць / Ред.: Я.В. Шрамко

Вип. 14. - Кривий Ріг, 2013, 70-82 
брак-гражданское состояние мужчины и женщины, их союз для образования семьи, рождения детей. В отличие от других социальных отношений брак включает в себя естественно-биологический элемент - интимную связь половых партнеров (сексуальные контакты), кроме этого, брачные отношения имеют экономическую, эмоционально-психологическую, правовую, моральную стороны [18, с. 136].

Истоки формирования идеала безбрачия в платонизме восходят, в первую очередь, к Сократу. В известном афоризме, приписываемом ему: «Женись непременно. Попадется хорошая жена-станешь счастливым. Плохая - станешь философом», имплицитно содержатся бракоборческие тенденции этического характера (счастливый брак не способствует духовному совершенствованию и философствованию). И хотя Сократ, в отличие от своего великого ученика, был женат, но свой брак он воспринимал, во-первых, как гражданский долг перед родным полисом (философу на момент вступления в брак было уже за сорок), а во-вторых, как метод этического самосовершенствования в условиях общения со строптивой и сварливой женщиной. Поэтому не случайно он говорил, что сварливая жена для него - то же, что норовистые кони для наездников: «Как они, одолев норовистых, легко справляются с остальными, так и я на Ксантиппе учусь обхождению с другими людьми» [4, с. 104]. Сократ воплощает в себе античный идеал мудреца, философа, непрестанного искателя истины. Бывало, Сократ по нескольку дней не возвращался домой. Его естественное времяпровождение - бесконечные рассуждения и диалоги. Такое поведение частично может служить оправданием сварливости Ксантиппы, воспринимающей Сократа как бездельника и болтуна. Таким образом, идеал философа, ведущего непрестанные поиски небесной истины и идеал брачной жизни, связанной с суетой этого мира, оказываются малосовместимы.

Онтологические, аксиологические и антропологические основания идеала безбрачия в платонизме кроются в учении орфизма, под влиянием которого античность свыкается с мыслью, что мир лежит во зле и что душа без отрицания тела не спасется для вечной жизни. В орфизме появляется дуализм духовного и телесного. Тело и чувственность воспринимаются как гроб души и обманчивый призрак. Человек предстает как смешение титанического и дионисийского начал [21, с.93]. Его задача - освободить душу из связанной вожделениями телесной темницы. Следовательно, аскетизм становится условием благочестивой жизни, вплоть до отказа от мясной пищи и отречения от всего, что связано с телесностью, в том числе и от брака (в частности, ор- 
фическим жрецам предписывалось строжайшее безбрачие).

Под влиянием смерти Сократа и с усилением орфико-пифагорейского влияния Платон приходит к отрицательному восприятию сферы телесно-эротических проявлений, которая является одним из отличительных признаков брака $[18$, с. 136]. Наиболее яркий полюс этой этико-аскетической позиции сосредоточен в «Федоне» [10]. Платон указывает, что философу не свойственно пристрастие к питью и еде и еще менее к любовным наслаждениям (64d). Душа философа решительно презирает тело и бежит от него на протяжении всей жизни (65c). Тело - темница души (83a), враг человека, оно наполняет нас вожделениями, эросами, страхами, призраками (66c), что наряду с безрассудством составляют сферу человеческого зла (81a). В данном случае Платон не случайно употребляет слово «эрос» во множественном числе $(\varepsilon \rho \omega \tau \omega \nu)[23,81 \mathrm{a}]$, показывая неразумную множественность плотской страсти. Поэтому, задача философа-как можно больше ограничить свою связь с телом, чтобы не быть зараженным его природой (66d-67b). Главной же целью философской жизни становится умирание и смерть (64а). И если философ останется верным своим идеалам, то его душа «уходит в подобное ей самой безвидное место, божественное, бессмертное, разумное, и, достигши его, обретает блаженство» (81a).

Рассуждения Платона имеют здесь не столько «эротоборческий» [22, с. 511-512, 532], сколько спиритуалистический характер. Философ говорит о страстной, пылкой любви, но не в качестве телесного вожделения, а в смысле желания обретения полноты разума (66d-e), что закрепляется даже терминологически. Говоря о любви к разуму, Платон употребляет глагол $\eta \rho \omega \nu$, одну из форм глагола $\varepsilon \rho \alpha \omega$, сокоренного эросу [23, 68a]. Таким образом, если идеал брака сложно представить без эротической составляющей, то Платон в «Федоне» во имя философии отрицает это чувственное начало в человеке, восстающее против разума, следовательно, идеал философствования расходится с идеалом брачной жизни.

В творчестве Платона на фоне аскетических воззрений на чувственность существуют и другие, дионисийские (оргийные) обертоны, представленные в «Федре» [11]. Но и здесь позиция мыслителя базируется вовсе не на идеале брака. В начале (первая речь Сократа) Платон представляет эрос в отрицательном («федоновском») смысле, как опаснейший вариант необузданности, возникающий от порабощения разумного начала врожденным стремлением к удовольствиям и наслаждению телесной красотой (238c), что мешает внутреннему со- 
вершенству (239b), отторгая человека от божественной философии. Но неожиданно с этой вершины аскетизма Платон делает резкий спуск в неистовство эротической мании. Он предлагает максимально использовать чувственность, от которой обычно отказываются все аскетические учения, проповедующие спасение души. По мнению Платона, десять тысяч лет вынуждена душа скитаться вдали от своей небесной родины, за исключением души человека, «искренне возлюбившего мудрость или сочетавшего любовь к ней с влюбленностью в юношей: эти души окрыляются за три тысячелетних круговорота» (249a). В этом синтезе Платон по-новому обосновывает основания аскезы Сократа. Как объясняет С. Семенова, за этим возбужденным физиологизмом «Федра» прослеживается «предельная конденсация» половой энергии: «Не будет внизу вулкана натурального пола, его огнедышащей энергии, не будет ничего и вверху, красоты умного, духовного космоса» [16, с. 164-165]. То есть, Платон как бы предлагает возбудить до максимума врожденное нам эротическое вожделение за счет телесной красоты, а затем за счет разума обуздать и перенаправить эту мощную энергию для служения правильным целям, в частности философии и спасению души.

Данные построения опять созвучны идеалу безбрачия. Во-первых, у Платона речь идет о влюбленности в юношей. Культ «любви к мальчикам», как указывает А. Лосев [7, с. 678-681, 683, 855], был неслучаен для Древней Греции, а вполне вытекал из ее культурных основ. Он связан с аксиологическим доминированием мужского начала, любовью мужчины к своему подобию (юноше), когда мужчина (зрелый ум) вожделеет к первым проблескам юношеского ума. Во-вторых, Платон ратует за необузданность эроса, кладет в его основание демонизм, что разрушительно для идеала брака. По мнению П. Рикера, человек всегда обретал человечность и очеловечивал свою сексуальность только через институт брака - дисциплину, во многом требующую жертв. По слову исследователя, между Эросом и институтом брака как бы заключен непрочный союз, полный противоречий, требующий жертв и страдания, порой даже деструктивный по отношению к человечности. В то же время ни одно из современных обществ не считает возможным отказаться от того, чтобы худо ли, бедно ли упорядочить и поставить под контроль демонизм Эроса с помощью института семьи [15, с. 225-226]. В-третьих, брак предполагает цель деторождения, а Платон предлагает использовать эротизм помимо этой цели. Как пишет С. Суровягин, «для страстной плотской и горячей „платоновской“ любви заключение брака - начало их гибели. Они, эти два вида любви, 
не стремятся иметь детей, как жизненно нужную цель» [19, с. 204].

В зрелом периоде своего творчества Платон синтезирует орфизм «Федона» и дионисизм «Федра». Данный синтез представлен в «Пире» [9]. Здесь уже нет эротомании «Федра», но и нет того тотального отрицания чувственности, как в «Федоне». «Пир», по сравнению с «Федром» и «Федоном», дышит классической умеренностью. Ключевая концепция «Пира»- это сотериологическая концепция восхождения за счет любви-эроса от менее значимых к более значимым благам и, наконец, к вечному Благу. Но вечностью, бессмертием нельзя овладеть сразу, люди овладевают ими постепенно. Тело обретает бессмертие через деторождение (206е). Оставляя всякий раз новое вместо старого (207d), телесное сохраняет свой род и числится прежним, хотя все время и меняется. Но этот путь использования эроса для родового бессмертия несовершенен, жажда бессмертия понуждает искать более высокие пути. От различных менее совершенных телесных порождений (дети) Платон переходит к более совершенным - душевным порождениям (прекрасные законы, речи), а далее и к созерцанию, от которого рождаются не признаки добродетелей, а добродетель истинная. Такому человеку достается в удел любовь богов, и если кто-либо из людей бывает бессмертен, то именно он (212a).

В данном диалоге уже во всей полноте предстает концепция «духовного» (спиритуалистического) брака с различением всеобщей и небесной любви. Представленная в «Пире» концепция любви также устремляется с горизонтали супружеского эроса (согласно речи Аристофана, каждый ищет благо в обретении своей телесной половины) в вертикаль философско-сотериологического эроса в речи и образе Сократа (душа должна обрести свою бестелесную половину в самом Благе). В качестве ступеней этого аксиологического восхождения у Платона выступают телесный брак (порождающий детей), душевный брак (порождающий законы и речи) и, наконец, духовный, созерцательный брак души и прекрасной идеи Блага (порождающий добродетели).

Социальным вопросам брака больше всего внимания Платон уделяет в «Государстве» [8]. По его мнению, проблема сохранения единства государства - это преимущественно проблема сохранения внутреннего единства среди сословия стражей, которому угрожает индивидуализм и обособленность интересов. Поэтому общие жены и дети - это величайшее благо идеального государства (457d). Но, естественно, беспорядочное совокупление, по мнению Платона, в идеальном государстве допускать нечестиво, следовательно он предлагает учреждать священ- 
ные браки (458c-е, 460а), которые напоминают скорее не идеальную любовь, а «конный завод» [7, с. 775] со строгими правилами (459de). Таким образом, супружеской любви Платон не придает серьезности и называет ее ребячеством (607e-608b), которое по бесполезности сродни поэзии. Предаваться любовным утехам и праздности - недостойная забава (426a), взаимная любовь не входит в интересы идеального общества. Любовь, по сути, нужна лишь в том незначительном объеме, для того чтобы утилитарно обеспечить совокупление мужчины и женщины с целью поддержания численности населения идеального государства.

В идеальном государстве человек должен следовать добродетельной жизни под руководством разума или, по определению А. Лосева, «умственно-физической гигиене» [6, с. 738], которая заключается в подражании космосу в его гармоничном соотношении души и тела. Платон приходит к идеалу проведения жизни без эротического неистовства. Эрос, как одно из проявлений вожделеющего начала, должен успокоиться и не мешать своими радостями и скорбями самому «благороднейшему в человеке», то есть разуму. Более того, эрос попадает в разряд лишенных необходимости вожделений, которые не приносят ничего хорошего (558c-559c), и от которых человек может избавиться, если приложит старания с юных лет. По мнению мыслителя, множество вожделений свойственно лишь женщинам и ничтожным людям, а у людей благородных они простые и умеренные (431c-d). У философа эти вожделения устремлены на приобретение знаний, сменяются влечением к подлинной философии (499b-c), что и доставляет его душе удовольствие, а телесные удовольствия для него пропадают, если он не притворно, а подлинно философ (485b-e).

Анализируя концепцию брака, представленную в «Государстве», исследователи подчеркивают его номинальный характер. По словам В. Асмуса, в идеальном государстве Платона для стражей возможна, в сущности, не семья, а лишь соединение мужчины с женщиной для рождения детей. Это тоже «брак», но брак своеобразный. Он увеличивает население, но неспособен привести к образованию семьи [1, с. 147]. Аналогичный вывод делает В. Виндельбанд. По сути, только отмена брака в учении Платона дает государству возможность заботиться о том, чтобы его граждане оставляли потомство, обладающее всеми требуемыми качествами, но этим уничтожается всякая семейная жизнь [3, с. 150].

А. Лосев ставит вопрос еще более остро: признает ли вообще строгий платоник брак или нет? По его мнению, античный платонизм до- 
пускает брак, но выбрасывает из него всякое духовное и личностное содержание. Платонизм признает необходимость физического рождения детей, но тут не должно быть ничего другого, кроме факта рождения, т.е. не должно быть ни семьи, ни отца, ни матери, ни детей (в собственном смысле), ни какой-нибудь любви. Платонически любить - значит брать ту женщину, которую прикажет правительство, и брать только на раз, с единственной целью - дать ей возможность стать беременной. Надо быть или монахом, или полицейским, или рабом-послушником, а быть отцом, быть матерью, быть сыном или дочерью вы не имеете никакого права. Браки декретируются правительством, которое обязано преследовать цели рода, цели государства, а вовсе никак не отвечать тем или иным чувствам своих граждан. Любить надо идеи, а не семью [7, c. 849-850].

Резюмируя позицию Платона, отметим, что идеал безбрачия еще не выражен у него в однозначной форме. Следуя в русле сотериологической традиции орфизма, земному браку он предпочитает «духовный» брак, но в то же время пытается воплотить свои взгляды через привычные социальные нормы в теории брака в идеальном государстве. В более четком виде идеал безбрачия предстает уже на завершающей стадии формирования платонизма - у Плотина, в творчестве которого дуализм духовного и телесного выражается еще более рельефно. Ведь не случайно Плотин не только не состоял в браке, но даже стыдился, что у него есть тело.

Плотин доводит до логического завершения платоновскую концепцию эроса, лежащую в основании «духовного» брака. В его учении эрос присутствует на всех ступенях эманации. Всецелая Душа и Душа Вселенной имеют каждая своего ипостасийного эроса, эроса-бога. Бог-эрос, эманируя далее, «рассыпается» на множество эросов-демонов, из принадлежности космической души - в принадлежность душ индивидуальных, в ту предельную расщепленность, которая в античности изображалась в веренице божков-эросов, когда каждая любовь, каждое любовное предприятие, каждый любовный оттенок имеет как бы своего Эроса, своеобразного бога мгновения, максимально соответствующего образу времени, а не единству вечности.

Суть эроса-демона-вожделение. Эрос-демон-вечно нуждающийся [13, III.5.5]. По мнению Плотина, любовь-эрос, наряду с другими проявлениями Блага, из-за ниспадения в материю вырождается.

И мы должны помнить, то, что исходит от божеств (звезд) не доходит до получателя в своем первоначальном виде; огонь, например, будет 
более тусклым; любовный инстинкт выродится в уродливые формы страсти [...] Любое из подобных качеств, сотворенное как нельзя лучше высшей формой, попав к нам, портится: любые вещи, приходящие к нам сверху, меняются уже потому, что они покинули место своего рождения, и продолжают меняться из-за слияния с телами, с материей, друг с другом [14, II 3.11.1-13].

Таким образом, эрос, который нам знаком по земным меркам, является искажением настоящего эроса, природа которого заключается в стремлении к богу, к простому (т.е. к Благу), а не к частичному. Это первичное влечение в душах должно быть «к красоте-в-себе», проявляться как «узнавание ее, сродство с ней и бессознательное чувство интимной близости к ней» [12, III 5.1]. В своем естественном состоянии душа «любит $(E \rho \alpha)$ бога, стремясь к единению с ним, как девушка любит прекрасного отца прекрасною любовью $(\varepsilon \rho \omega \tau \alpha)$. Когда же она как бы ослепляется браком, придя к рождению, она меняет на другого смертного эроса, и дерзкою жизнью живет вдали от отца. Возненавидев же здешнюю дерзость и очистившись от здешнего, она снова обращается с силой к отцу и испытывает состояние блаженства» [12; 24, VI.9.9.33-46]. Описывая это блаженство возвращения души к богу, Плотин замечает:

Кому не известно, сколь блаженно это состояние души, тот может составить приблизительное представление о нем по аналогии с тем упоением, которое дается людям и здесь в тот момент, когда их любовные стремления ( $\varepsilon \rho \alpha)$ осуществляются, с тем, однако, ограничением, что все, служащее здесь предметом любви $(\varepsilon \rho \omega \mu \varepsilon \nu \alpha)$ и желаний, тленно и призрачно, ... что не среди этого рода вещей находится то, что мы можем действительно любить ( $\varepsilon \rho \omega \varepsilon \nu о \nu)$, что составляет наше истинное благо, к чему мы стремимся, но только там - Тот, который поистине достоин нашей любви, Тот, с которым легко можно войти в общение и союз, так как Он не имеет на себе никакой телесной оболочки [14, 24, VI 9.9.38-46].

Соответственно главная суть эроса-бога - истинное созерцание. Данную характеристику Плотин вводит в связи с некоторой недосказанностью платоновского «Пира», в котором при восхождении последовательно преодолеваются характеристики эроса как стремления и порождения, а в результате остается только созерцание. При этом не совсем ясно, что происходит с эросом по достижении им цели желания. Платоновский эрос, достигнув идеального, по сути должен был бы исчезнуть, сменившись созерцанием. Плотин разрешает это затруднение, переходя от эроса-демона (стремящегося) к эросу-богу (созерцающему). 
Сопоставляя эрос и созерцание, Плотин даже сам термин «эрос» выводит от термина «зрение», «видение», «взирание», указывая, что

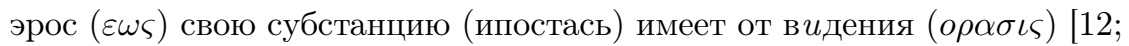
24, III.5.3.13-15]. Этот эрос-взор, по Плотину, появляется, когда Афродита интимно сближается с Кроносом (или Ураном), то есть божественная душа обращается к божественному уму, и результатом этого является дающий возможность видеть эрос-бог, который есть «око вожделеющего, благодаря своим силам дающий влюбленному видеть предмет его вожделения» [13, III.5.2.40-41]. Здесь представлено более четкое, по сравнению с Платоном, внесение самого эроса в зрительные интуиции. Эрос высшей души, по Плотину, проявляется как «созерцающий и сам пребывающий в высоте, поскольку он спутник высшей души, ею и из нее рожденный, довольный созерцанием богов» $[12$, III.5.3.19-21]. Следовательно, путь нашей души к небесному пристанищу обратен эманации и будет проходить от эроса-вожделения к эросусозерцанию.

Обобщая эти рассуждения Плотина, можно сказать, что эрос естественный - есть эрос к богу (эрос-созерцание), а искаженный проявляется в виде брачного (эрос-вожделение). Подобным образом у Плотина различаются и две Афродиты: одна - небесная, другая - имеющая отношение к здешним бракам [12, III.5.2]. Подобное противопоставление земной и небесной любви встречается и у Платона, но у Плотина оно представлено в более резкой форме.

Как и у Платона, эрос в учении Плотина может быть стремлением как к образу, так и к первообразу, скрытому за материей. Задачей человека становится от чувственного образа прийти к воспоминанию первообраза, любить этот образ как отображение первообраза. На этом пути возможна ошибка, когда чувственный образ представляется единственно истинным, и тогда сближение с красотой может вызвать грех соития. То есть непогрешительно лишь созерцать красоту, а вступление же в физическое соитие, по мнению Плотина, есть грех [12, III.5.1.28-46]. Таким образом, Плотин, в отличие от Платона, плотское совокупление уже прямо называет грехом. По его мнению, лишь только «остающиеся целомудренными не совершают ошибки в усвоении этой [чувственной] красоты» [13, III.5.1.36-38].

В данных рассуждениях Плотина слышатся все те же орфические мотивы, которые вдохновляли Платона, только в более резких интонациях. Зло - это материя. В «Эннеадах» все красоты этого чувственного мира предстают сомнительными и загрязненными через их помещение в материю. Разве можно допустить, спрашивает Плотин, чтобы 
истинные красоты могли валяться в плотской грязи, выпачканные до неузнаваемости [14, VI 7.31]. Поэтому те, кто озабочены лишь продолжением своего рода, здесь, на земле, довольствуются земной красотой, красотой образа и плоти, находятся лишь в начале своего пути $[14$, III.5.1]. Попытка увековечить себя через деторождение оказывается для Плотина низменной. Выше всего оказывается та любовь, которая вовсе не стремится рождать физически [5, с. 631].

Какой же жизнью тогда должен жить человек согласно Плотину? Как подчеркивает П. Блонский, он должен жить жизнью чистой души, обращенной к уму, так как истинный, внутренний человек, подлинное наше «я», есть душа, ум, для которого жизнь в теле-зло, а бегство «отсюда»- нравственная заповедь [2, с. 279]. Такая душа оставляет все здешнее вне своего внимания, стремится к истинному [14, VI 7.31], спешит выйти отсюда, ненавидит то, «что нас связывает с иным, чтобы всею целокупностью нас самих обвить его и не иметь ни одной части, которой бы мы не соприкасались с богом» [5, с. 640].

$\mathrm{K}$ такой жизни ведут человека музыка, эротика и философия. Музыкант восприимчив к красоте, стремится к соразмерности и мере. Задача музыканта - отличая материальные формы от истинно-сущих, прийти к абсолютной красоте [14, I 3.1]. Второй тип - рожденные любить ( $\varepsilon \rho \omega \tau \iota \kappa o \varsigma)$, которые влюблены в красоту, хранят в своей памяти как бы отблески истинной красоты. Их задача - распознавать красоту во всем и понять, что в основе красоты Единое. Им следует показать красоту бестелесного, красоту наук, добродетелей [14; 24, I 3.2]. Но самый высший тип - философы. Они, в отличие от прочих, уже окрылены, но нуждаются в руководстве.

Вечные ученики, они легко освоят математику, которая поможет сформировать у них абстрактное мышление и веру в умопостигаемое и бестелесное; нравственным по своим природным склонностям, им следует постоянно совершенствоваться в добродетелях; после математики они должны постигнуть диалектику и стать искусными в этой науке [14, I 3.3].

Таким образом, если у Платона сотериологические идеи («Федон», «Федр», «Пир») уравновешиваются социальными идеями («Государство»), в которых брак, хоть и в номинальном значении, но служит образованию всеобщей гармонии, то у Плотина мы встречаем идеал единичного человека, безбрачного философа. В нем, по словам Вл. Соловьева, предстает лишь отрешенный от мира созерцатель и аскет, стыдящийся, что имеет тело, соответственно собирательный человек (общество) никогда не достигает здесь пределов человечества. 
Так как высшая жизненная задача исчерпывается здесь возвращением единичной души к богу, то в этом воззрении нет места для общественных, политических и исторических задач: все дело происходит между отдельным лицом и «неизреченным» абсолютом [17, с. 396-397]. Следовательно, самое главное в жизни человека - путь к спасению у Плотина можно обозначить через три главных идеала: философское созерцание, аскетизм и безбрачие.

Рассмотрев проблему идеала безбрачия в платонизме, мы пришли к следующим выводам. Бракоборческие мотивы платонизма имплицитно содержатся еще в рассуждениях и образе жизни Сократа. Их суть можно охарактеризовать через несовместимость счастливого брака и философии. Брак для Сократа предстает более как гражданский долг и возможность для этического совершенствования. Под влиянием образа учителя, а также дуалистических и сотериологических идей орфизма в философии Платона формируется концепция «духовного» брака («Федон», «Федр», «Пир»). Однако идеал безбрачия еще не выражен у него в явной форме. В более четком виде он предстает уже на завершающей стадии формирования платонизма - у Плотина. Идеал безбрачия тесно связывается здесь с сотериологическим становлением души человека, которое проявляется в философском созерцании и аскетизме.

\section{Литература}

[1] Асмус В.Ф. Платон. - М. : Мысль, 1975.

[2] Блонский П.П. Философия Плотина.-М.: Товарищество типографии А.И. Мамонтова, 1918.

[3] Виндельбанд В. Платон. - К. : Зовнішторгвидав України, 1993.

[4] Диоген Лаэртский. О жизни, учениях и изречениях знаменитых философов. - М. : Мысль, 1986.

[5] Лосев А.Ф. История античной эстетики. Поздний эллинизм. - М. : АСТ; Харьков: Фолио, 2000.

[6] Лосев А.Ф. История античной эстетики. Софисты. Сократ. Платон. - М. : АСТ; Харьков: Фолио, 2000.

[7] Лосев А.Ф. Очерки античного символизма и мифологии. - М.: Мысль, 1993. 
[8] Платон. Государство // Платон. Сочинения в 4 т. - М.: Мысль, 1994. - T. 3. - C. 79-420.

[9] Платон. Пир // Платон. Сочинения в 3 т. - М.: Мысль, 1970. T. 2. - C. 95-156.

[10] Платон. Федон // Платон. Сочинения в 3 т. - М. : Мысль, 1970. T. 2. - C. 11-94.

[11] Платон. Федр // Платон. Сочинения в 3 т. - М. : Мысль, 1970. T. 2. - C. 157-222.

[12] Плотин. Об Эросе // История античной эстетики. Поздний эллинизм. - М. : АСТ; Харьков: Фолио, 2000. - С. 619-630.

[13] Плотин. Третья эннеада. - СПб. : Изд-во Олега Абышко, 2004.

[14] Плотин. Эннеады. - К. : УЦИММ-Пресс, 1995.

[15] Рикер П. История и истина. - СПб. : Алетейя, 2002.

[16] Семенова С.Г. Любовь - это стремление к бессмертию // Философия любви. В 2 ч. Ч. 1. - М. : Политиздат, 1990. - С. 162-204.

[17] Соловъев В.С. Платон и Плотин (Статьи из Энциклопедического словаря Брокгауза и Ефрона) // Платон: pro et contra. Платоническая традиция в оценке русских мыслителей и исследователей: Антология. - СПб. : Изд. Русского Христианского гуманит. ин-та, 2001. - C. 364-397.

[18] Социология: Энциклопедия / Сост. А.А. Грицанов и др. - Минск : Книжный Дом, 2003.

[19] Суровягин С.П. Философия семьи. Цель семьи. Главенство в семье. Любовь и брак. - Тюмень : Вектор Бук, 2000.

[20] Троицкий C. Христианская философия брака // В. Соловьев. Смысл любви; С. Троицкий. Христианская философия брака; Протоиерей Иоанн Мейендорф. Брак в православии. - М. : Путь, 1995. - C. 53-215.

[21] Трубецкой С.Н. Курс истории древней философии.-М.: ВЛАДОС ; Русский Двор, 1997. 
[22] Эрн В.Ф. Верховное постижение Платона // Эрн В.Ф. Сочинения. - М. : Правда, 1991. - С. 463-532.

[23] Plato. Phaedo [Electronic resource CD ROM] // Thesaurus Linguae Graecae. Key 59.4 / University of California. - Irvine, 2000. - Reprint.: Platonis opera, vol. 1. - Oxford: Clarendon Press, 1967. - P. St I.57a-118a.

[24] Plotinus. Enneades [Electronic resource CD ROM] // Thesaurus Linguae Graecae. Key 2000.1 / University of California. - Irvine, 2000. - Reprint.: Plotini opera, 3 vols. — Leiden: Brill, 1951-1973.

Надійшла до редакції 25 квітня 2013 р. 